\title{
Sistem Pengontrol Asap Rokok di Area Bebas Rokok Ruangan Tertutup
}

\author{
Noviana a, Dwi Cahyono ${ }^{b}$ \\ a Universitas Dr. Soetomo, Surabaya, Indonesia \\ b Universitas Dr. Soetomo, Surabaya, Indonesia \\ email: ${ }^{a}$ novianakurdi@gmail.com, ${ }^{b}$ dwik@unitomo.ac.id \\ INFORMASI
}

ARTIKEL

Sejarah artikel:

Accepted Oktober 2021

Kata kunci:

Sistem Pendeteksi

Siste Perngontrol

Sensor MQ- 02

Asap rokok

Node MCU

Kipas

\section{A B S T R A K}

Asap rokok sangat berbahaya bagi kesehatan karena mengandung berbagai bahan kimia yang dapat menyebabkan berbagai macam penyakit seperti batuk kronis, kanker paru-paru, dan gangguan kesehatan lainnya. Masih banyak manusia yang merokok, meskipun telah mengetahui bahwa asap rokok berbahaya bagi kesehatan. Asap rokok tidak hanya membahayakan kesehatan perokok itu sendiri melainkan juga kesehatan orang lain yang berada disekitarnya, karena senyawa- senyawa yang terkandung dalam asap rokok yang tetap berada di udara terhirup oleh orang lain di sekitar kawasan tersebut. Kegiatan merokok selain merusak diri sendiri juga membahayakan orang lain yang ikut menghirup asapnya. Kawasan bebas asap rokok di Negara ini masih sangat minim terlebih dengan sangat minimnya hukuman bagi pelanggar. Penelitian ini fokus pada perancangan alat untuk memantau suatu ruangan bebas dari asap rokok. Alat pengendali polusi asap rokok ini, bekerja dengan cara mengeluarkan asap rokok pada suatu ruangan, kemudian dengan sistem otomatis dapat mengembalikan kesegaran udara pada ruangan tersebut. Masukan dari sistem ini adalah sensor MQ-02 yang mendeteksi asap rokok sehingga menghasilkan tegangan output dan kemudian diolah dalam Node MCU. Arduino akan memerintahkan driver untuk mengaktifkan kipas pembuangan, buzzer dan akan mengirimkan notifikasi kepada Website penjaga ruang.Berdasarkan uji coba yang telah dilakukan, sensor Mq-02 yang digunakan untuk mendeteksi asap pada ruangan tertutup cukup sensitif, hal ini dapat ditunjukkan pada pengujian dengan hasil precision sebesar $100 \%$, recall sebesar $73 \%$ dan accuary sebesar $73 \%$

(c) 2021 INFOTRON: Jurnal IImiah Teknik Informatika, Elektronika dan Kontrol (Scientific Journal of Informatics, Electronics and Control Engineering). Copyrights. All rights reserved.

\section{Pendahuluan}

Kebiasaan merokok merupakan hal yang dapat dijumpai di tempat-tempat umum. mengingat banyaknya penyakit yang ditimbulkan oleh asap rokok maka pemerintah terus berupaya meningkatkan pencegahan larangan merokok di tempat umum dengan membuat kebijakan tentang kawasan bebas asap rokok yang sesuai dengan peraturan pemerintah Republik Indonesia. Kebiasaan merokok telah terbukti merupakan penyebab terhadap kurang lebih 25 jenis penyakit yang menyerang berbagai organ tubuh manusia[2]. Rokok sebenarnya tidak baik bagi kesehatan manusia. Rokok yang terbuat dari daun tembakau kering, kertas dan zat perasa, dibentuk dari unsur Carbon $(\mathrm{C})$, Hidrogen $(\mathrm{H})$, Oksigen $(\mathrm{O})$, Nitrogen $(\mathrm{N})$, Sulfur $(\mathrm{S})$, serta unsur- unsur lain. Hal tersebut dapat menganggu kenyamanan dan merusak kesehatan orang lain. Bukan hanya membahayakan para perokok, asap juga sangat berbahaya apabila dihirup oleh orang- orang yang berada disekitarnya (perokok pasif). Sistem pendeteksi asap rokok di ruangan tertutup sangat membantu untuk menetralisir dan menyegarkan kembali udara yang ada pada ruangan bebas asap rokok. 
Seiring berkembangnya teknologi yang semakin pesat, banyak manfaat yang dirasakan manusia dalam melakukan aktivitasnya. Manfaat itu diantaranya adalah mengatur keamanan ruangan agar terhindar dari asap rokok dan nyala api. Pengaturan terhadap asap rokok dan nyala api perlu dilakukan untuk menghindari kebakaran ruangan dan menjaga kesehatan, khususnya kesehatan pernapasan yang disebabkan oleh gas beracun yang ada di dalam ruangan tersebut. Asap rokok sangat berbahaya bagi kesehatan karena mengandung berbagai bahan kimia yang dapat menyebabkan berbagai macam penyakit seperti batuk kronis, kanker paru-paru, dan gangguan kesehatan lainnya. Masih banyak manusia yang merokok, meskipun telah mengetahui bahwa asap rokok berbahaya bagi kesehatan. Asap rokok tidak hanya membahayakan kesehatan perokok itu sendiri melainkan juga kesehatan orang lain yang berada disekitarnya, karena senyawa- senyawa yang terkandung dalam asap rokok yang tetap berada di udara terhirup oleh orang lain di sekitar kawasan tersebut[1].

Mengingat banyaknya penyakit yang ditimbulkan oleh asap rokok maka pemerintah terus berupaya meningkatkan pencegahan larangan merokok di tempat umum. Kebijakan yang dilakukan antara lain membuat kebijakan tentang kawasan bebas asap rokok dan memberi peringatan tertulis tentang larangan merokok yang ditempel pada tempat-tempat umum yang mudah terlihat. Kebijakan ini telah diterapkan di gedung-gedung perkantoran, pendidikan, rumah sakit, dan juga tempat umum lainnya. Peringatan tertulis ini sering tidak dipatuhi oleh para perokok aktif. Perokok masih sering terlihat merokok ditempat-tempat umum dan terbuka yang mengakibatkan udara menjadi terkontaminasi oleh asap rokok yang sangat berbahaya untuk kesehatan tubuh manusia.

Berdasarkan permasalahan tersebut, perlu adanya Sistem yang mampu mendeteksi Asap Rokok yang berada di suatu ruangan. Asap rokok dapat dideteksi dengan piranti elektronika yang disebut dengan sensor. Beberapa penelitian sebelumnya telah menggunakan sensor MQ-09 untuk aplikasi mendeteksi kebocoran gas LPG dan asap rokok. Informasi tentang asap rokok di suatu ruangan dikirim ke pengguna melalui layanan short message secvice (SMS) agar pengguna dapat melakukan tindakan pencegahan terhadap asap rokok dan nyala api yang terjadi. GSM SIM900A merupakan salah perangkat yang dapat digunakan untuk berkomunikasi kepada pengguna melalui layanan SMS[3]. Pada penelitian ini, telah dibuat alat pendeteksi asap rokok yang menggunakan sensor MQ- 02 yang merupakan sensor yang digunakan untuk mendeteksi konsentrasi gas yang mudah terbakar di udara serta asap dan output membaca sebagai tegangan analog. Sensor gas asap MQ-2 dapat langsung diatur sensitifitasnya dengan memutar trimpotnya. Sensor ini biasa digunakan untuk mendeteksi kebocoran gas baik di rumah maupun di industri. Gas yang dapat dideteksi diantaranya: LPG, ibutane, propane, methane, alcohol, Hydrogen, smoke[4].

Pada penelitian perangkat pendeteksi ini mampu mengirimkan notifikasi atau pesan singkat sesuai dengan kondisi yang di tentukan melalui Website.

\section{State Of the Art}

Penelitian tentang Perancangan Sistem Pendeteksi Asap Rokok ini sebelumnya sudah pernah di buat oleh Putri Mandarani, Mahasiswa Teknik Informatika, Institut Teknologi Padang, Padang, Tahun 2016 dengan judul "Perancangan Sistem Deteksi Asap Rokok Menggunakan Layanan Short Message Service (SMS) Alert Berbasis Arduino", penelitian tersebut melakukan sebuah uji coba untuk mengetahui tingkat presisi dan akurasi sensor MQ- 02 yang digunakan sebagai sistem pendeteksi. Uji coba dilakukan sebanyak 8 kali dengan masing-masing keluaran asap rokok yang berbeda yang berbeda setiap kali percobaan[1]. Hasil pengujian alat pada penelitian sebelumnya dapat dilihat pada tabel 1.

Tabel 1. Hasil Pengujian alat Penelitian Terdahulu

\begin{tabular}{ccc}
\hline Menit Ke- & Kondisi & $\mathrm{V}$ \\
\hline 1 & Tidak Ada Asap & 0,66 \\
2 & Tidak Ada Asap & 0,63 \\
3 & Tidak Ada Asap & 0,61 \\
4 & Tidak Ada Asap & 0,58
\end{tabular}




\begin{tabular}{lll}
\hline 5 & Ada Asap & 0,77 \\
6 & Ada Asap & 0,90 \\
7 & Ada Asap & 1,04 \\
8 & Ada Asap & 1,50 \\
\hline
\end{tabular}

Penelitian berikutnya yang dilakukan oleh Valentina br Ginting, Bisman Perangin-angin, Takdir Tamba dengan judul "Sistem Pengendalian Asap Rokok Multikanal Dengan Menggunakan Pwm Berbasis Mikrokontroller Atmega 8"[5]. Sistem kerjanya yaitu jika di dalam ruangan terdeteksi asap rokok oleh sensor MQ 2 maka mikrokontroler akan menampilkan data sesuai dengan kadar asap pada LCD.Mikrokontroler akan mengaktifkan alarm dan mengaktifkan kipas, dan penelitian ini juga dilengkapi dengan PWM merupakan suatu metode untuk mengatur kecepatan perputaran motor dengan cara mengatur lebar pulsa high terhadap perioda dari suatu sinyal persegi dalam bentuk tegangan periodik yang diberikan ke motor DC sebagai sumber daya.

\section{Method}

Dalam pengembangan Sistem Pendeteksi Asap Rokok Lanjutan ini memerlukan sebuah metodologi waterfall yaitu mengerjakan sesuatu sesuai urutan dengan cara bertahap agar sistem dapat berjalan lancar. Berikut beberapa tahapan tersebut[6]:

a. Studi Literatur

Tahap pencarian informasi, teori yang relevan untuk menyelesaikan persoalan dengan menelusuri sumber-sumber tulisan yang dapat dijadikan sebagai bahan studi pustaka.

b. Tahap Pengembangan

Pada tahap pengembangan system yang akan dibuat menggunakan metode waterfall. Adapun tahap- tahap metode waterfall sebagai berikut:

1) Tahap Analisa Kebutuhan

Pada tahap ini menganalisa kebutuhan tentang perangkat keras dan data- data yang dibutuhkan dan dirancang agar efisien digunakan serta mengecek apakah kebutuhan perangkat keras dan data yang akan digunakan sudah lengkap.

2) Tahap Desain Sistem

Pada tahap ini akan memperkirakan bagaimana perangkat keras satu sama lain dapat saling terhubung dan berjalan menjadi sebuah mesin.

3) Tahap Implementasi

Pada tahap ini desain sistem yang telah disusun sebelumnya akan diubah menjadi kodekode program dan modul- modul yang nantinya akan diintegrasikan menjadi sebuah sistem yang lengkap.

4) Tahap Pengujian Program

Pada tahap ini akan dilakukan serangkaian pengujian terhadap kinerja dan ketahanan alat. pada pengujian dilakukan dengan mencoba beberapa kali sensor MQ-02 untuk mengetahui keakuratan sensor untuk mendapatkan hasil yang maksimal.

5) Tahap Pemeliharaan

Pada tahap ini akan dilakukan proses pemeliharaan termasuk memperbaiki kesalahan/ bug yang tidak ditemukan pada tahap pengujian program.

\section{Hasil dan Pembahasan}

Pada tahap ini akan dilakukan pengujian terhadap perangkat keras yang telah dirancang atau dibuat, mulai dari pengujian input sensor MQ-02, dan uji aksi dari sistem pendeteksi asap rokok Gas CO2 di area bebas rokok ruang tertutup. Pengujian ini dilakukan untuk menguji dan memperbaiki modul perangkat keras maupun perangkat lunak tersebut. Dari hasil uji coba ini akan dilakukan evaluasi apakah hasilnya telah sesuai dengan yang diharapkan dan juga nantinya pengujian ini digunakan sebagai acuan untuk pengembangan sistem kearah yang lebih baik lagi. Pada penelitian ini pengujian 
menggunakan Uji coba black box adalah uji coba berdasarkan kriteria kebenaran masukan (input), keluaran (output) dan juga aksi dari sistem pengendalian waktu penyiraman otomatis.

a. Rangkaian Sensor MQ-02

Pada proses pertama yaitu memasang sensor Mq-02 pada prototype

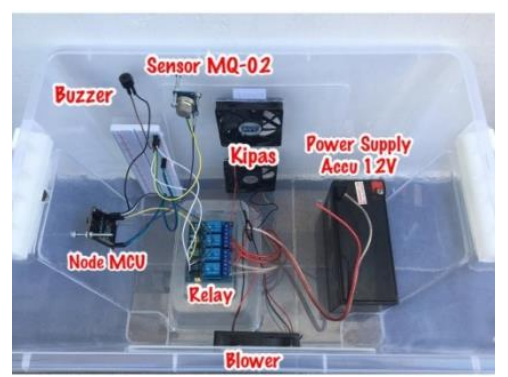

Gambar 1. Sensor MQ-02 Pada Prototype

Pada tahap rangkaian sensor ini menghitung nilai yang ada pada sensor MQ-02 kemudian setelah sistem pada prototype ini bekerja sistem akan bekerja sesuai kondisi yang di tentukan.

b. Rangkaian Accu Pada Prototype

Pada sistem pendeteksi asap rokok gas $\mathrm{CO} 2$ di area bebas rokok ruang tertutup ini, catu daya yang diperoleh guna memenuhi kebutuhan daya hardware yang dibuat berasal dari accu motor $12 \mathrm{v}$ itu sendiri.

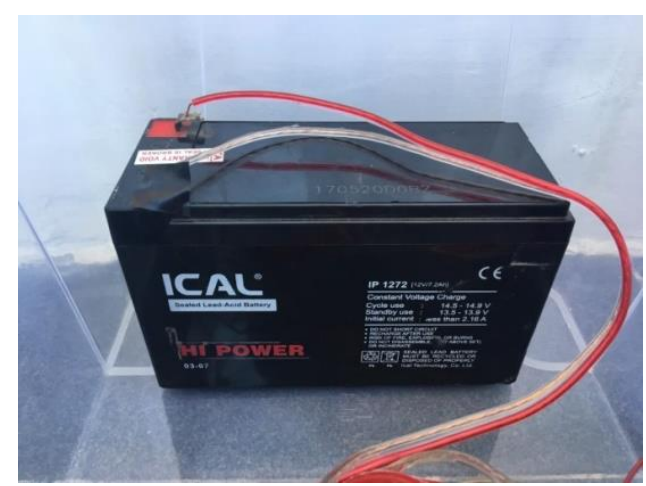

Gambar 2. Rangkaian Accu Pada Prototype

Gambar 2 menunjukan dalam proses pembuatan alat ini menggunakan komponen elektronik yang berupa mikrokontroler, sensor dan aktuator yang semuanya membutuhkan catu daya $12 \mathrm{v}$.

c. Rangkaian relay dengan kipas dan blower

Rangkaian relay yang telah dibuat tersebuat maka kemudian dipasangkan pada kipas dan blower seperti pada gambar 3 . 


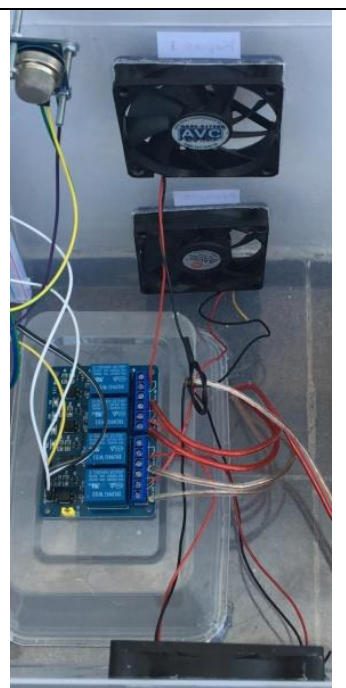

Gambar 3. Rangkaian Relay

d. Hasil rangkaian yang telah terpasang total

Setelah semua komponen mulai kipas, blower, accu, relay, node mcu, sensor mq-02 terpasang semuadalam satu rangkaian prototype dalam box. Maka alat siap untuk di uji coba menggunakan asap rokok. Untuk lebih jelasnya dapat dilihat pada gambar 4.

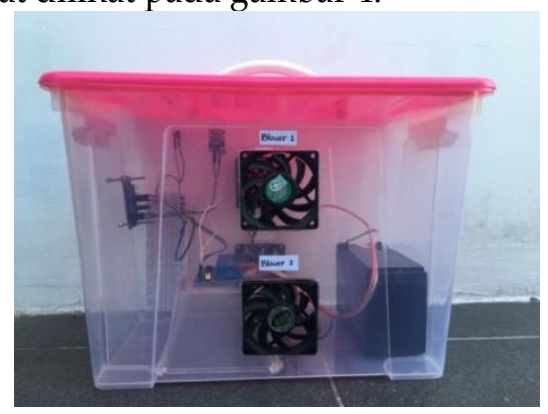

Gambar 4. Hasil Rangkaian yang telah terpasang total

e. Hasil Pengujian Sensor MQ- 02

Pengujian ini bertujuan untuk mengetahui ketepatan kinerja sensor MQ-02 terhadap akurasi asap. Pada alat ini pengujian dilakukan dengan adanya asap yang nilainya sudah tersimpan didalam modul sensor. Untuk proses pembacaan asap rokok membutuhkan waktu $<5$ detik agar sensor mq-02 dapat terbaca.

Tabel 2. Hasil Pengujian Sensor MQ- 02

\begin{tabular}{llllll}
\hline No & Nilai Asap & \multicolumn{1}{c}{ Notifikasi } & Status Kipas & Status Blower & Pembacaan \\
\hline 1 & 321 & Ruangan Bebas Dari Asap & Mati & Mati & Valid \\
2 & 188 & Ruangan Bebas Dari Asap & Mati & Mati & Valid \\
3 & 346 & Ruangan Berasap Sedang & k1 Nyala & B1 Nyala & Valid \\
4 & 201 & Ruangan Bebas Dari Asap & Mati & Mati & Valid \\
5 & 806 & Ruangan Berasap Tebal & K1\&K2 Nyala & B1 \& B2 Nyala & Valid \\
6 & 508 & Ruangan Berasap Sedang & k1 Nyala & B1 Nyala & Valid \\
7 & 320 & Ruangan Bebas Dari Asap & Mati & Mati & Tidak Valid \\
8 & 480 & Ruangan Bebas Dari Asap & Mati & Mati & Tidak Valid \\
9 & 230 & Ruangan Bebas Dari Asap & Mati & Mati & Valid \\
10 & 497 & Ruangan Berasap Sedang & k1 Nyala & B1 Nyala & Valid \\
& & & & & \\
\hline
\end{tabular}




\begin{tabular}{rrllll}
\hline 11 & 734 & Ruangan Berasap Tebal & K1\& K2 Nyala & B1 \& B2 Nyala & Valid \\
12 & 595 & Ruangan Berasap Sedang & K1\& K2 Nyala & B1 \& B2 Nyala & Valid \\
13 & 308 & Ruangan Bebas Dari Asap & Mati & Mati & Tidak Valid \\
14 & 1.023 & Ruangan Berasap Tebal & K1\& K2 Nyala & B1 \& B2 Nyala & Valid \\
15 & 798 & Ruangan Berasap Sedang & K1\& K2 Nyala & B1 \& B2 Nyala & Tidak Valid \\
\hline
\end{tabular}

1. Keterangan Tabel :

2. $\mathrm{K} 1=$ Kipas 1

3. $\mathrm{K} 2$ = Kipas 2

4. $\mathrm{B} 1=$ Blower 1

5. $\mathrm{B} 2=$ Blower 2

Pada tabel 2 terdapat 15 kali uji coba Asap yang nilainya range sudah di inputkan. Pada nilai Asap yang berbeda dilakukan uji coba berulang kali agar dapat menghasilkan nilai confidance yang berbeda. menunjukan hasil dari uji coba sebanyak 15 kali yang menunjukan tingkat keberhasilan sebesar $78 \%$ Nilai confidance ini didapatkan dari hasil pembacaan sensor MQ-02 asap yang dibaca untuk memastikan seberapa besar nilai tingkat kepercayaan modul Sensor MQ-02 dengan asap yang dibaca.

Meskipun tingkat kepercayaan setiap kali uji coba mendapat hasil yang berbeda namun data tetap dapat dinyatakan tidak valid. Hal ini dipengaruhi oleh beberapa faktor kondisi asap yang masuk ke dalam ruangan dan faktor angin yang membawa asap.

\section{Kesimpulan}

Kesimpulan yang dapat diambil dari perancangan dan Sistem Pendeteksi Asap Rokok (GASCO2) di area bebas rokok ruang tertutup:

a. Berdasarkan uji coba yang telah dilakukan, Sistem Pendeteksi Asap Rokok dengan adanya pengiriman data pada cloud penyimpanan dan dapat ditampilkan pada layar smartphone dan desktop.

b. Data asap rokok dalam ruangan dapat ditampilkan melalui website.

c. Berdasarkan uji coba yang telah dilakukan, sensor Mq-02 yang digunakan untuk mendeteksi asap pada ruangan tertutup cukup sensitif, hal ini dapat ditunjukkan pada pengujian dengan hasil precision sebesar $100 \%$, recall sebesar $73 \%$ dan accuary sebesar $73 \%$.

\section{Refrensi}

[1] P. Mandarani et al., "Perancangan Sistem Deteksi Asap Rokok Menggunakan Layanan Short Message Service ( Sms ) Alert Berbasis Arduino," J. TEKNOIF, vol. 4, no. 2, pp. 66-75, 2016, doi: 10.21063/JTIF.2016.V4.2.66-75.

[2] N. Rahmah, “Pengaruh Rokok Terhadap Kesehatan dan Pembentukan Karakter Manusia," Pros. Semin. Nas., vol. 01, no. 1, p. 78, 2015.

[3] F. puri Himawan, U. Sunarya, and D. A. Nurmantris, "Perancangan Alat Pendeteksi Asap Berbasis Mikrokontroller, Modul GSM, Sensor Asap, Dan Sensor Suhu," E-Proceeding Appl. Sci., vol. Vol.3 No., no. 3, pp. 1963-1968, 2017.

[4] Jiankai.li, “Grove - Gas Sensor ( MQ2 ) User Manual,” Seed Grow Differ., vol. 1, p. 16, 2015.

[5] T. T. Valentina br Ginting, Bisman Perangin-angin, "Sistem Pengendalian Asap Rokok Multikanal Dengan Menggunakan Pwm Berbasis Mikrokontroler Atmega 8," vol. 3, no. 2252, pp. 58-66, 1828, [Online]. Available:

http://www.tjyybjb.ac.cn/CN/article/downloadArticleFile.do?attachType=PDF\&id=9987.

[6] Sommerville. Ian, Software Engineering 9th, 9th ed. Addison-Wesley, 2011. 